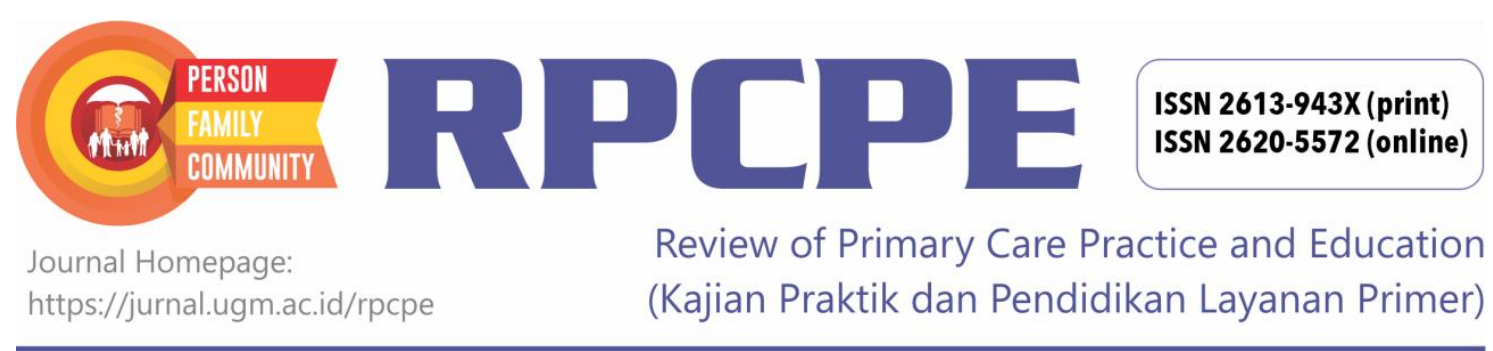

\title{
The Role of Primary Care in End of Life Care
}

\author{
Aghnaa Gayatri ${ }^{1}$
}

\author{
${ }^{1}$ Department of Family and Community Medicine; Faculty of Medicine, Public Health and Nursing; Universitas Gadjah Mada, \\ Indonesia \\ Corresponding Author: \\ Aghnaa Gayatri: Department of Family and Community Medicine; Faculty of Medicine, Public Health and Nursing; Universitas \\ Gadjah Mada, Indonesia, Jl. Farmako, Sekip Utara, Gd. Radiopoetro, Lt. 1, Sayap Barat, Yogyakarta - 55281, Indonesia \\ Email:aghnaa@yahoo.com.au \\ To cite this article: \\ Gayatri A. The role of primary care in end of life care. Rev Prim Care Prac and Educ. 2018; 1(2): 53-55.
}

\section{INTRODUCTION}

Primary Care has been acknowledged to be the solution towards the achievement of "Health for All" as declared in the Declaration of Alma Ata ${ }^{1}$. Its importance has been further emphasized in the World Health Organization (WHO) 2008 Report $^{2}$, where the changing world is in dire need of health care that surpasses all boundaries and can be delivered to all. It is stated that current health systems that are mostly hospital-based pose the risk of fragmented and uncoordinated care for the people. The move towards primary care is aimed at solving this problem amongst many others.

One of the features that distinguishes primary care from other levels of care is that it addresses the needs of people irrespective of their age, gender, and disease, thus caring for individuals from the very beginning of life until death $^{3}$. Caring for the dying patient has been traditionally considered as palliative or hospice care which is being provided to terminally ill patients in secondary settings ${ }^{4}$. With the shift of population by the increasing of elderly people, chronic conditions also become a major health problem which can eventually lead to death, and these often occur at homes and at the nursing care centers ${ }^{5}$. Care for the dying patient should not be just about preparing the patient for death. It is important to manage the dying patient in terms of management of symptoms and providing psychological support. Primary care situated as the first line of health care has an important role in ensuring that end of life care is well provided from the earliest stage possible, in coordination with other services when necessary.

\section{END OF LIFE CARE}

The term palliative care is the most common term used in literatures when discussing patient care at the end of their life. The $\mathrm{WHO}^{6}$ defines palliative care as "an approach that improves the quality of life of patients and their families in facing the problem associated with life-threatening illness, through the prevention and relief of suffering by means of early identification and impeccable assessment and treatment of pain and other problems, whether physical, psychosocial and spiritual". A simpler definition can be obtained from The National Council for Palliative Care ${ }^{7}$, where end of life care is defined as "the provision of supportive and palliative care in response to the assessed needs of patient and family during the last phase of life". This definition addresses the need of the provision of care in regards to the patient's and family's need, suggesting a person-centered approach to the care.

It used to be that end of life care was considered to be for those with terminal illnesses such as cancer. Nowadays, with the growing number of elderly people, chronic diseases are become a major health burden, and a major cause of death in the population. People are increasingly dying of serious chronic diseases such as the heart failure, stroke, and COPD (Chronic obstructive pulmonary disease). Especially with the multiple conditions that usually occur in elderly patients, it can be difficult to identify with certainty which of the chronic diseases is the main cause of death. It might be that several conditions that occur simultaneously are all contributing to the patient's death.

There are three distinct illness trajectories as explained by Lynn and Adamson ${ }^{8}$ for people with chronic disease. These are the steady progression of illnesses which usually have an apparent terminal stage (mostly cancer); the gradual decline condition with episodes of acute decline of health with recovery stage followed by a sudden, unexpected death; and the prolonged gradual decline that is commonly encountered in the frail elderly or those with dementia. These trajectories generate the need for palliative care to 
be provided not only when death is seemingly predicted, but also in conditions that lead to a gradual and long period of the dying phase. It rejects the perception that palliative care is only of importance to the last few weeks of life and can only be provided by specialized services. The difficulty of predicting the course of many chronic illnesses in the elderly drives the need for end of life care to be based on the needs of the patient and family rather than on a definite prognosis.

\section{BRINGING END OF LIFE CARE TO PRIMARY CARE}

Primary care is an engaging approach in providing care. It is on its own a complex multidimensional system that aims to achieve high quality, efficient care, and create equity in health. Its process of care ensures that care for all members of the population is accessible in a continuous, comprehensive, and coordinated manner in the setting of communities. Reforms in healthcare call for the need of a person-centered approach to care, rather than the traditional disease oriented model, to reduce fragmented and uncoordinated care. It intends to shift the majority of healthcare provision from hospitals to communities, to be able to take into account all the determinants of health. Patients are considered as partners in health, and care is provided in the basis of mutual understanding, fulfilment of their needs, and not just the cure of their illness. These are the characteristics of primary care that enable it to provide care for any group of patients within the community ${ }^{3}$.

Palliative care specialists often focus on patients who are terminally ill such as those with malignancy. This creates a situation where older people with chronic diseases living at home often do not receive adequate care during the last stages of their life. It drives the need for palliative care services to be available outside the secondary setting and be moved into the primary care setting. The position of primary care which is within the community is another characteristic that can suggest why the end of life care should be carried out by primary care teams. End of life care services from primary care create an opportunity to extend supportive care at an earlier stage, to those not only with cancer but also with chronic diseases. In addition, the continuous relationship of patients with their primary care providers makes it easier for primary care teams to develop care plans that will better suit the patient's need. Positioning primary care in the control of the end of life care for these patients will help patients and families feel more comfortable with the decisions made for their care from a team with whom they have a valued long-term relationship.

The lack of a single contact point in this patient group creates a fragmented and uncoordinated care, and primary care is best situated as the center of this integration to solve this problem. From the way primary care is positioned, primary care will act as the hub of the integration between services. It is able to create a network between services within the community that is being served and also between other levels of health care. Not only will it help coordinate communication between services, putting primary care in charge for the patient's end of life care will connect patients and families with services needed that might not be easily accessible to them without the role of a gatekeeper, helping them to navigate their way through the different levels of the health care system.

\section{CONSEQUENCES}

Providing end of life care in the primary care setting means that primary care teams must be equipped with palliative care skills. Primary care physicians should have the ability in the management of the symptoms and acute problems that may arise during the course of the disease, whether it is at the patient's home or in nursing care. This may not be achieved when General Practitioners (GPs) are not equipped with the right skills. Lack of skilled professionals can limit the quality and quantity of care that can be delivered in the end of life care. Identification of those in need of end of life care is also important. This has been proven to be somewhat problematic as there is no definite clinical state that defines patients as being in the end of life stage, especially when the progression of chronic diseases varies from one patient to another ${ }^{9}$. It is the reason why the end of life care is often introduced late, when a terminal decline has started. Studies show that there seems to be various understandings in GPs on who is considered as a person in need of end of life care ${ }^{10,11}$.

Communicating the process of dying and initiating participation of patients in the making of care plans is an issue for both the primary care team and the patients and their families ${ }^{12}$. The primary care team must have effective communication skills in informing patients about their disease progress, as well as their options of care at their end of life, as these can be a sensitive matter. Our society does not talk openly about the death and dying process, thus it is important to equip the primary care team with effective communication skills. The care plans should be carefully formulated by the patient and the primary care team. When the patient and family are not well informed about their progress of illness, decisions regarding their care plans will be difficult to make.

\section{CONCLUSION}

The movement toward strengthening of primary care shifts the provision of healthcare from a disease oriented and hospital-based care, towards a person-centered community approach targeted to all members of the population. This movement is applicable in all care settings, including end of life care for the elderly. Shifting the end of life care from secondary settings to primary care ensures the ability of patients to obtain care from a team that they are familiar with. With the complex problems that accompany elderly patients, the availability of a primary care team can facilitate and coordinate the different types of care that are needed. Though it seems that bringing the end of life care to the primary care setting is the solution to reduce fragmented and uncoordinated care for the elderly patient, implications to the workforce and system must be addressed. Skilled workforce must be available in order for provision of end of life care in the primary care setting to be successful. 


\section{REFERENCES}

1. WHO-UNICEF. Declaration of Alma-Ata: International conference on primary health care [Accessed 1 st Nov 2014]. Alma-Ata, USSR, 6-12 September 1978 [Online]. Available from: http://www.who.int/publications/almaata_declaration_en.pdf

2. WHO. The world health report 2008: Primary health care now more than ever. Geneva: World Health Organizatioin. 2008.

3. Starfield, B. Is primary care essential?. Lancet. 1994;344:11291133.

4. World Health Organization Europe. The solid facts: Palliative care. Copenhagen: WHO. 2004.

5. World Health Organization Europe. Better palliative care for older people. Copenhagen: WHO. 2004.

6. World Health Organization. WHO definition of palliative care [Accessed on 20th November 2014]. Available from http://www.who.int/cancer/palliative/definition/en/

7. Department of Health (DH). End of life care strategy. Department of Health. 2008.

8. Lynn J, Adamson DM. Living well at the end of life: adapting health care to serious chronic illness in old age. Arlington, VA: RAND Health. 2003.

9. Murtagh FEM, Preston M, Higginson I. Patterns of dying: palliative care for non-malignant disease. Clinical medicine 2004;4(1):39-44.

10. Silveira MJ, Forman J. End-of-life care from the perspective of primary care providers. J Gen Intern Med. 2012;27(10):1287-93. doi: 10.1007/s1 1606-012-2088-3

11. Shipman C, Gysels M, White P, Worth A, Murray SA, Barclay S, et al. Improving generalist end of life care: a national consultation with practitioners, commissioners, academics, and service user groups. BMJ 2008;337:a1720. doi: 10.1136/bmj.a1720

12. Boyd K, Murray SA. Recognising and managing key transitions in end of life care. BMJ. 2010;342:C4863. 